\title{
FUNCTIONAL OUTCOME OF CLOSED METACARPAL FRACTURES TREATED WITH MINI FRAGMENT PLATES AND SCREWS
}

\author{
P. V. Pugalenthi' ${ }^{1}$ K. Ravichandran², N. Thanappan ${ }^{3}$, J. Maheswaran 4 , D. Sivaraman 5 \\ 1 Professor, Department of Orthopaedics, Madurai Medical College, Madurai. \\ ${ }^{2}$ Assistant Professor, Department of Orthopaedics, Madurai Medical College, Madurai. \\ ${ }^{3}$ Associate Professor, Department of Orthopaedics, Madurai Medical College, Madurai. \\ ${ }_{4}^{4}$ Assistant Professor, Department of Orthopaedics, Madurai Medical College, Madurai. \\ ${ }^{5}$ Postgraduate Student, Department of Orthopaedics and Traumatology, Madurai Medical College, Madurai.
}

\section{BACKGROUND}

ABSTRACT

Metacarpal fractures are common in adolescents and young active individuals. Mostly these are treated by conservative methods. In unstable fractures where closed reduction and final outcome are unsatisfactory, there are multiple surgical options for treating metacarpal fractures like K-wire fixation, interosseous wiring, plate osteosynthesis, etc. In this study, we assess functional outcome of closed metacarpal fractures treated with plates and screws.

\section{MATERIALS AND METHODS}

Between 2014 and 2016, 20 cases of closed metacarpal fractures were studied. Fracture was approached by dorsal incision. Plate configurations were chosen according to the fracture pattern (straight plate for shaft fractures, $\mathrm{T}$ or L configured plates were used for periarticular fractures) and fixed with screws. Post-operative physiotherapy and followup carried out.

\section{RESULTS}

In our study, all the cases showed bone union (100\%). The functional result assessed by American Society for Surgery of the Hand (ASSH) Total Active Flexion score showed excellent result in $80 \%$ of the patients (16 of 20 cases), good in $10 \%$ of cases (2 of 20 cases). Stable and rigid fixation allowed early mobilisation of fingers thereby preventing stiffness and achieved overall good functional results. Although there were $10 \%$ (2 cases) of superficial infections, all settled with regular dressing and antibiotics without affecting final functional outcome. The overall results are satisfactory.

\section{CONCLUSION}

Plate and screw fixation is a good option for treating closed unstable metacarpal fractures, where other modalities of fixation are less effective. The rigid stable fixation provided by plating which withstands load without failure allowed early mobilisation and achieved good functional results.

\section{KEYWORDS}

Metacarpal Fractures, Mini Fragment Plates and Screws.

HOW TO CITE THIS ARTICLE: Pugalenthi PV, Ravichandran K, Thanappan N, et al. Functional outcome of closed metacarpal fractures treated with mini fragment plates and screws. J. Evolution Med. Dent. Sci. 2017;6(33):2752-2761, D0I: $10.14260 /$ Jemds/2017/593

\section{BACKGROUND}

\section{Aim of the Study}

Metacarpal fractures are common in adolescents and young active individuals. Functional outcome of these fractures depend upon severity of injury and the achievement of treatment. Mostly these are treated by conservative methods[1]. Unstable fractures ${ }^{[2]}$ where closed reduction and final outcome are unsatisfactory are treated by operative measures. There are multiple surgical options for treating metacarpal fractures like K-wire fixation,[3] interosseous wiring, ${ }^{[4]}$ plate osteosynthesis,[5] etc.

In this study, we assess functional outcome of closed metacarpal fractures treated with plates and screws using

Financial or Other, Competing Interest: None.

Submission 13-03-2017, Peer Review 11-04-2017,

Acceptance 17-04-2017, Published 24-04-2017.

Corresponding Author:

Dr. P. V. Pugalenthi,

\#No 45, West Cross, Shanmugapuram,

Karupayurani (Po), Madurai-20.

E-mail: drpugalortho@gmail.com

DOI: $10.14260 /$ jemds $/ 2017 / 593$ the American Society for Surgery of the Hand (ASSH) Total Active Flexion (TAF) score.

\section{Objectives of the Study}

1. To study the various mechanisms and pattern of metacarpal fractures and their surgical management with plates and screws.

2. To study the functional outcome of metacarpal fractures treated surgically.

3. To study the technical difficulties and complications of metacarpal fractures treated surgically.

\section{Inclusion Criteria}

1. Age more than 18 years.

2. Physical fitness for surgery.

3. Sex- Both male and female.

\section{Exclusion Criteria}

1. Age less than 18 years.

2. Patient not willing or medically unfit for surgery.

3. Compound injury. 


\section{Indications}

Indications for plate fixation of the metacarpals are-

1. Multiple fractures with gross displacement.

2. Displaced diaphyseal transverse, short oblique, or short spiral fractures.

3. Comminuted intraarticular and periarticular fractures displaced.

4. Comminuted fractures with shortening or malrotation or both.

\section{MATERIALS AND METHODS}

\section{Source of Data}

Adult patients with metacarpal fractures admitted to Govt. Rajaji Hospital, Madurai will be taken up for study after obtaining the consent.

Period of Study- From Sep. 2014 to Sep. 2016.

\section{Design of the Study- Prospective.}

\section{Method of Collection of Data}

Patients with metacarpal fractures are selected after clinical and radiological analysis during the period of study from Sep. 2014 to Sep. 2016

All the patients selected for study will be examined according to protocol, associated injuries noted and clinical and lab investigations carried out in order to get fitness for surgery.

Consent of the patient will be taken for surgery. Patient will be followed till Union is achieved clinically as well as radiologically.

Time required for union, range of motion of surrounding joints and complications before/during/after surgery will be studied in detail.

Minimum of 20 cases was studied.

\section{Age Distribution}

Age group varied from 20 years to 70 years with mean age of 45 years. Incidence of fracture was observed maximum between 20 - 50 years.

\begin{tabular}{|c|c|c|}
\hline Age group & Number of cases & Percentage \\
\hline $20-29$ & 6 & 30 \\
\hline $30-39$ & 6 & 30 \\
\hline $40-49$ & 5 & 25 \\
\hline $50-59$ & 2 & 10 \\
\hline $60-70$ & 1 & 5 \\
\hline \multicolumn{3}{|c|}{ Age Distribution } \\
\hline
\end{tabular}

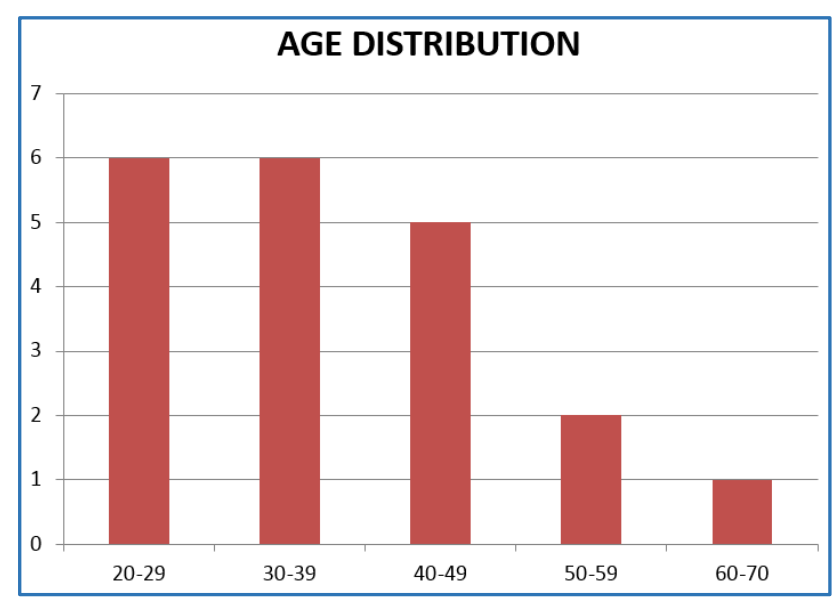

\section{Sex Distribution}

Among the 20 cases, males were predominant.

\begin{tabular}{|c|c|c|}
\hline Sex & Number of Cases & Percentage \\
\hline Male & 18 & 90 \\
\hline Female & 2 & 10 \\
\hline \multicolumn{3}{|c|}{ Sex Distribution } \\
\hline
\end{tabular}

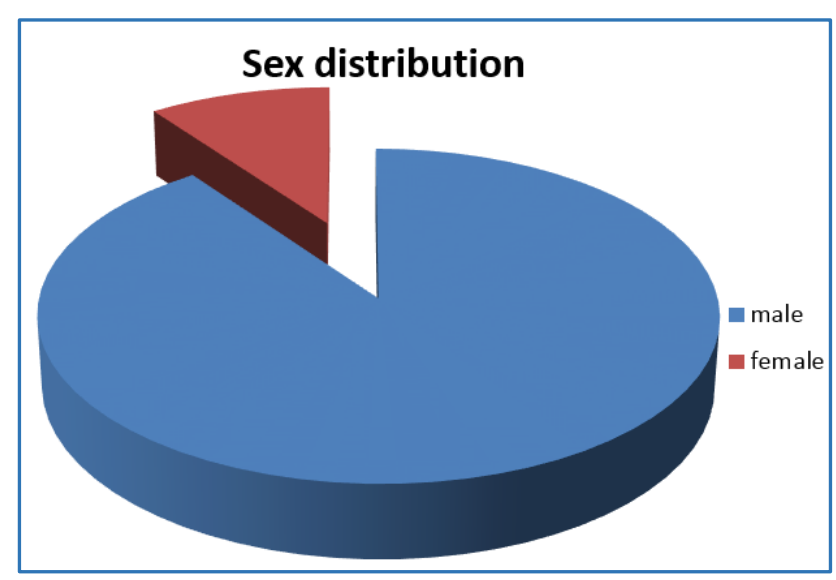

\section{Side of Injury}

\begin{tabular}{|c|c|c|c|c|}
\hline Sex & Right & Left & Bilateral & Total \\
\hline Male & 9 & 9 & 0 & 18 \\
\hline Female & 2 & 0 & 0 & 2 \\
\hline Percentage & 55 & 45 & - & - \\
\hline \multicolumn{5}{|c|}{ Side of Injury } \\
\hline
\end{tabular}

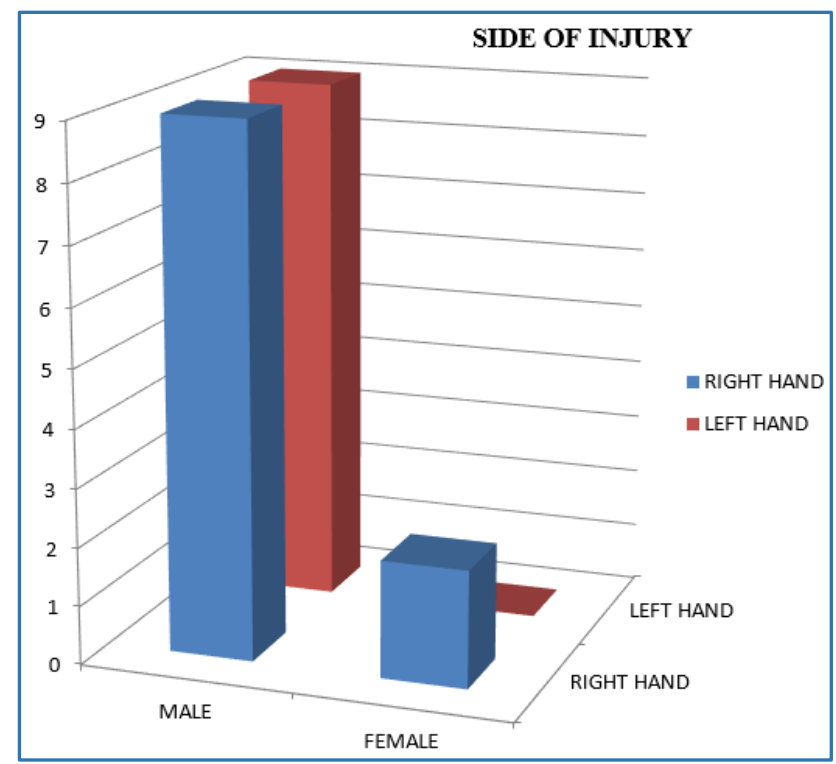

Mode of Injury

Commonest mode of injury being Road Traffic Accident (RTA).

\begin{tabular}{|c|c|c|}
\hline Mode of Injury & No of Cases & Percentage \\
\hline RTA & 11 & 55 \\
\hline Accidental Fall & 7 & 35 \\
\hline Assault & 2 & 10 \\
\hline \multicolumn{3}{|c|}{ Mode of Injury } \\
\hline
\end{tabular}




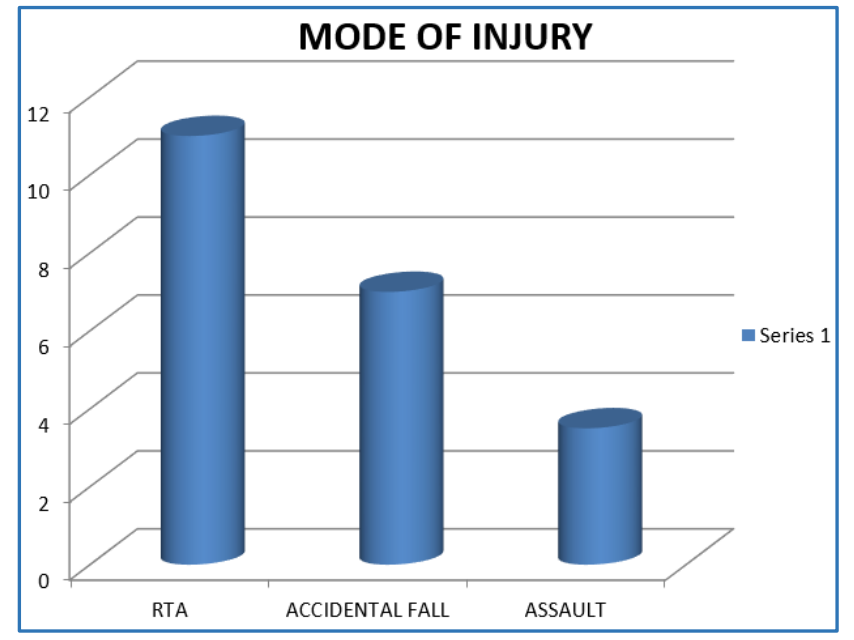

Classification of Fractures

\begin{tabular}{|c|c|c|}
\hline Fracture Location & No. of Cases & Percentage \\
\hline Head & - & - \\
\hline Neck & 2 & 10 \\
\hline Shaft & 16 & 80 \\
\hline Base & 2 & 10 \\
\hline \multicolumn{2}{|c|}{ Classification of Fractures } \\
\hline
\end{tabular}

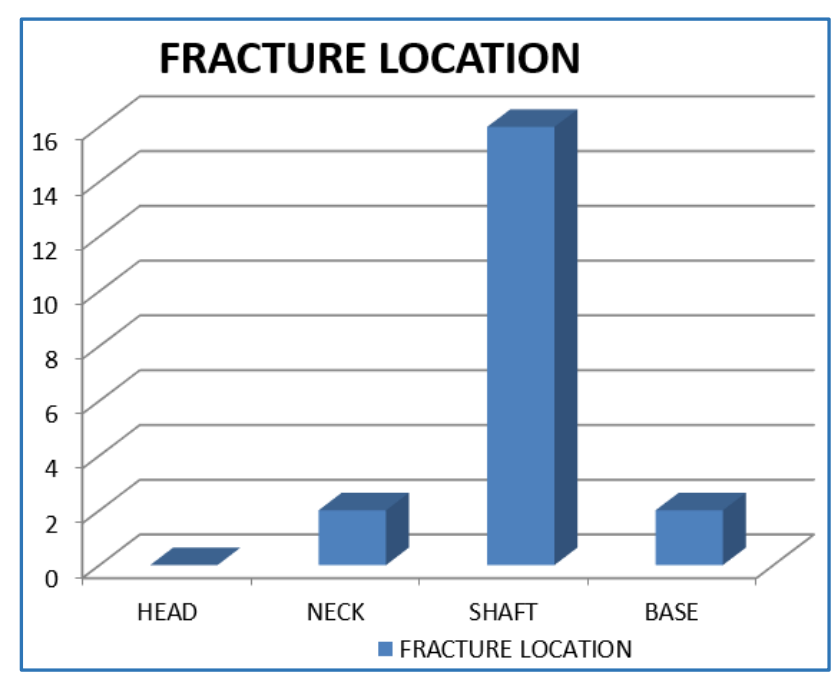

Number of Metacarpal Involved

Single metacarpal involvement being the most common accounting for $70 \%$ of the cases.

\begin{tabular}{|c|c|c|}
\hline $\begin{array}{c}\text { No. of Metacarpals } \\
\text { Involved }\end{array}$ & No. of Cases & Percentage \\
\hline 1 & 14 & 70 \\
\hline 2 & 5 & 25 \\
\hline 3 & 0 & - \\
\hline 4 & 1 & 5 \\
\hline 5 & 0 & - \\
\hline \multicolumn{2}{|c|}{ Number of Metacarpals Involved } \\
\hline
\end{tabular}

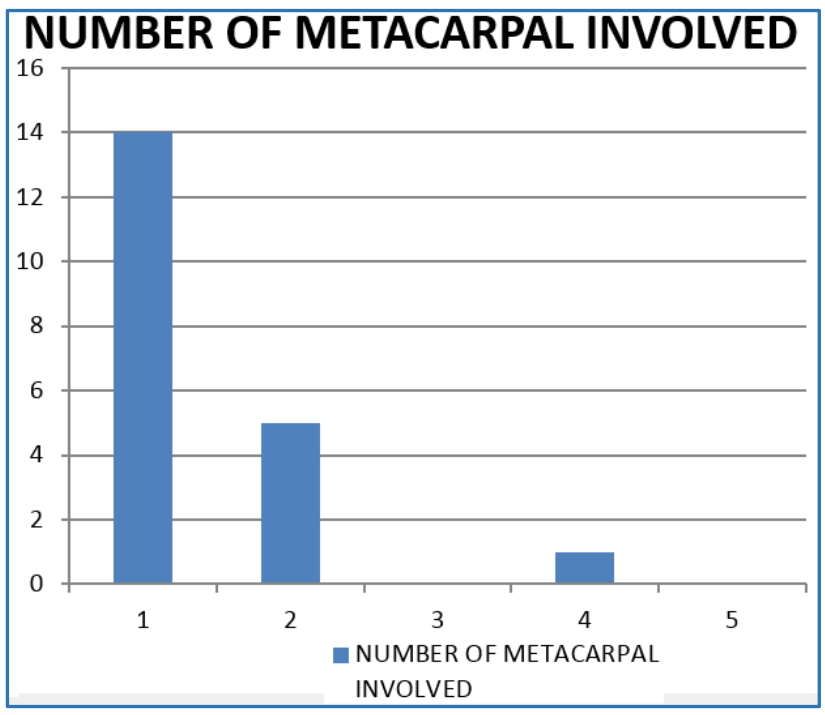

\section{Fracture Pattern}

Transverse fracture pattern being most common accounting for $50 \%$.

\begin{tabular}{|c|c|c|}
\hline Fracture Configuration & Number of Cases & Percentage \\
\hline Spiral & 7 & 35 \\
\hline Oblique & 2 & 10 \\
\hline Transverse & 10 & 50 \\
\hline Comminuted & 1 & 5 \\
\hline \multicolumn{2}{|c|}{ Fracture Pattern } \\
\hline
\end{tabular}

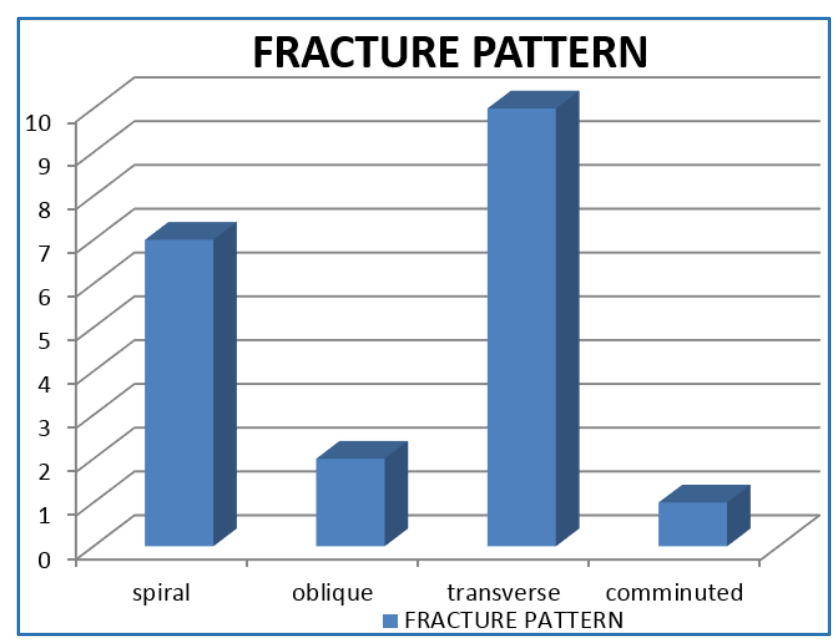

Time Interval between Injury and Surgery

\begin{tabular}{|c|c|c|}
\hline $\begin{array}{c}\text { Time Interval } \\
\text { (Days) }\end{array}$ & $\begin{array}{c}\text { No. of } \\
\text { Cases }\end{array}$ & Percentage \\
\hline$<2$ & 19 & 95 \\
\hline $3-5$ & 0 & - \\
\hline$>5$ & 1 & 5 \\
\hline \multicolumn{2}{|c|}{ Time Interval between Injury and Surgery } \\
\hline
\end{tabular}




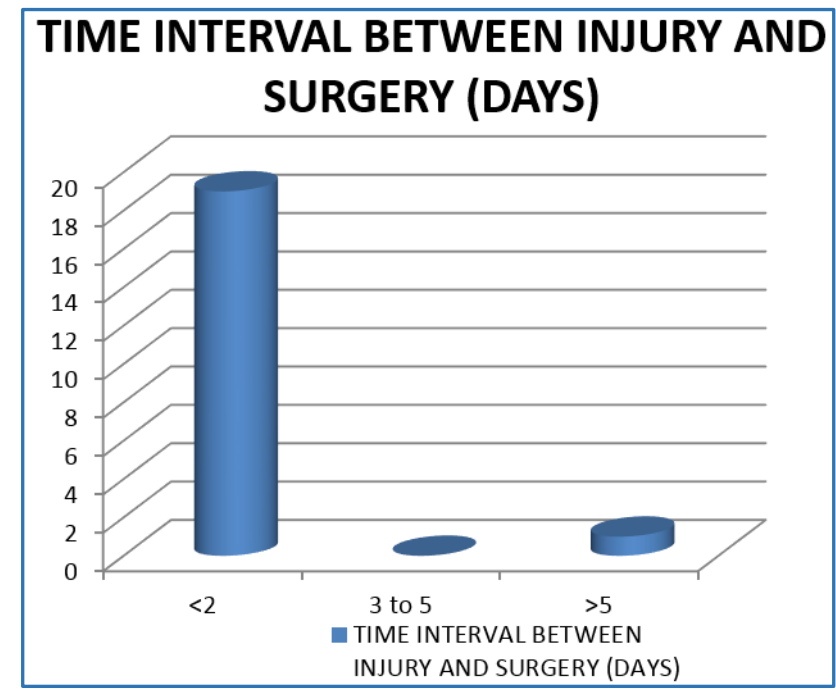

\section{Associated Injuries}

4 Cases had associated other bony injuries.

Fracture of shaft of ulna $\quad-\quad 1$

Fracture of shaft of $5^{\text {th }}$ metatarsal- 1

Fracture of both bones, leg $\quad$ - 1

Isolated fibular fracture $\quad-\quad 1$

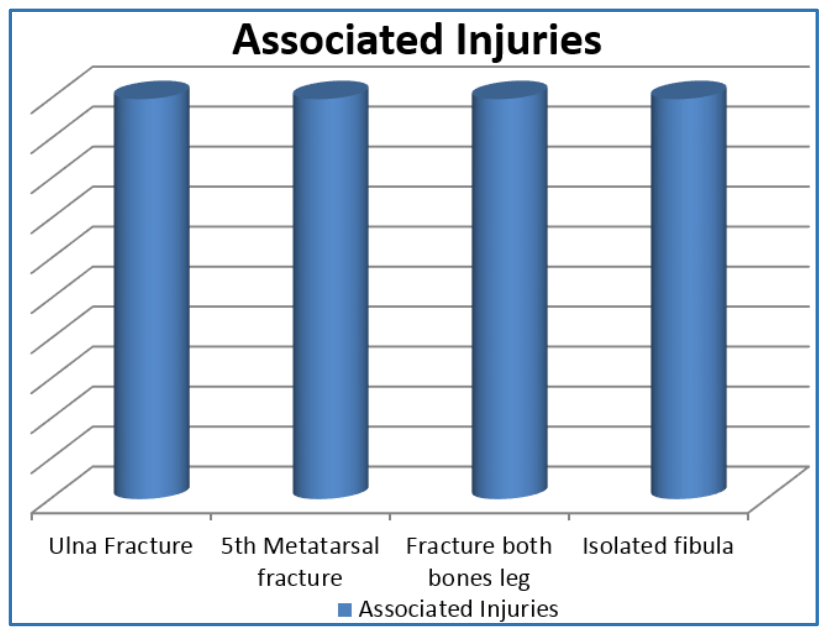

\section{Complications}

4 Cases developed complications. Infection seen in $10 \%$ (2 out of 20 cases). Stiffness seen in $10 \%$ ( 2 out of 20 cases).

\begin{tabular}{|c|c|c|}
\hline & No. of Cases & Percentage \\
\hline Infection & 2 & 10 \\
\hline Stiffness & 2 & 10 \\
\hline Tendon Irritation & - & \\
\hline Non-Union & - & \\
\hline Mal-Union & - & \\
\hline Implant Breakage & - & \\
\hline \multicolumn{3}{|c|}{ Complications } \\
\hline
\end{tabular}

\section{Union Time}

In most of the cases bony union was achieved in 6-7 weeks accounting for $65 \%$.

\begin{tabular}{|c|c|c|}
\hline Duration in Weeks & No. of Cases & Percentage \\
\hline $6-7$ & 13 & 65 \\
\hline $8-9$ & 6 & 30 \\
\hline$>9$ & 1 & 5 \\
\hline \multicolumn{2}{|c|}{ Union Time } \\
\hline
\end{tabular}

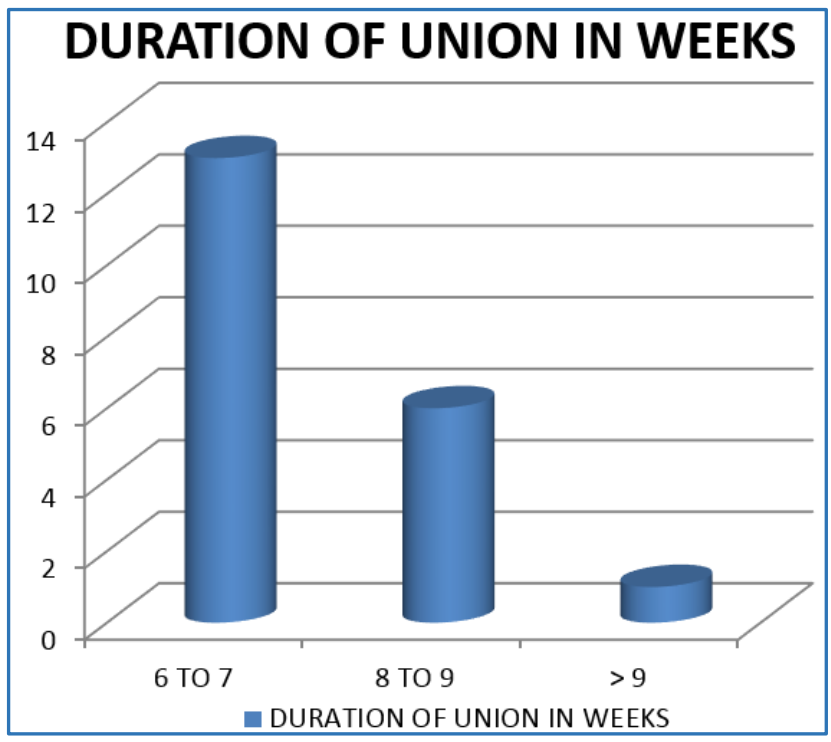

Pre-Operative Preparation

Base line blood investigations, $\mathrm{x}$-rays -pre-op, post-op.

A minimum of two views - anteroposterior and oblique are mandatory for assessing-

1. Degree of angulation.

2. Amount of shortening.

3. Presence of comminution.

\section{Procedure and Postoperative Protocol}

All patients were admitted in casualty department and were resuscitated. If there were any major associated injuries they were treated accordingly at first. After the general condition of the patient improved, radiographs - anteroposterior and oblique views were taken. Fracture reduced in closed manner at first under sedation and volar below elbow slab was applied. Unstable fractures were taken up for surgery - open reduction and internal fixation with plate osteosynthesis.

Most of the cases were taken up for surgery on the $1^{\text {st }}$ or $2^{\text {nd }}$ day of admission. Patients who were associated with major injuries were taken up for surgery between 5 to 7 days after admission.

Surgical Procedure- Open Reduction Internal Fixation with Plate Osteosynthesis

Tourniquet was used in all the cases before surgery.

Metacarpal fractures are approached by a dorsal incision[6] made on radial border for the first and second metacarpal, ulnar border for the fifth metacarpal. For the $3^{\text {rd }}$ and $4^{\text {th }}$ metacarpals, the approach is made using a dorsal longitudinal incision made between these bones. Then extensor tendons were retracted and anatomical reduction of the fracture fragments are carried out. Reduction is held using point reduction forceps or a stabilising $\mathrm{K}$ wire. Interfragmentary lag screws were used in long spiral and oblique fractures. Plate configuration were chosen according to the fracture pattern (Straight plate for shaft fractures, T or L configured plates were used for periarticular fractures) [7] and fixed with screws. Meticulous attention was carried out in soft tissue dissection and adequate soft tissue coverage (Periosteum) was made over the plate to avoid irritation to overlying extensor tendon. Thorough wound wash was given and wound closed without drain. Splinting of the hand was done with a volar below elbow slab. 


\section{Post-Operative Protocol}

Hand was kept in elevation for 24-48 hours for controlling pain and swelling. Wound was inspected at second postoperative day. Thereafter, active mobilisation of fingers started and increased progressively within the limits of pain tolerance. Patients were discharged on $5^{\text {th }}$ post-operative day and physiotherapy ${ }^{[8]}$ carried out on outpatient basis. Sutures were removed on $10^{\text {th }}$ postoperative day.

Followup was done at $4^{\text {th }}, 6^{\text {th }}$ and $8^{\text {th }}$ weeks and assessed for clinical progress in terms of range of movements and radiological evaluation done to note fracture union or any loss of reduction.

\section{Clinical Pictures}

Case 1

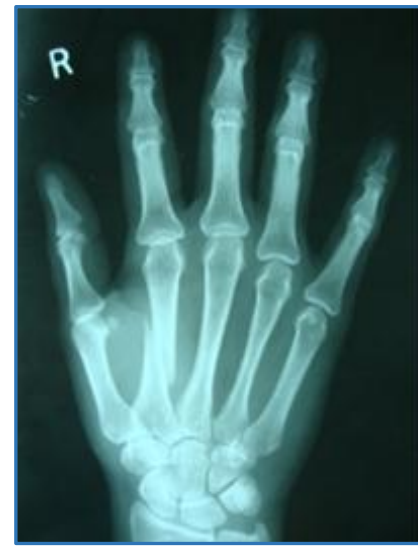

Pre-op X-ray

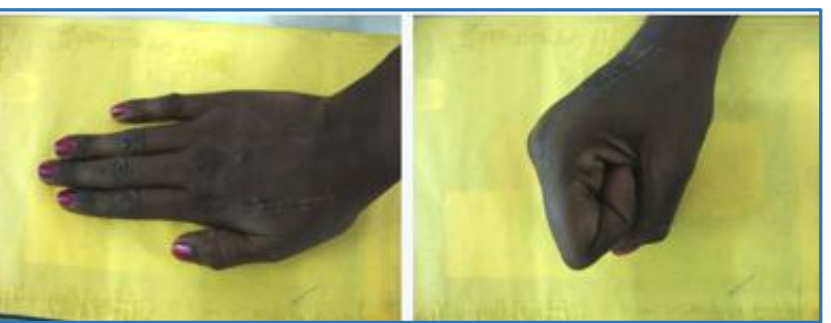

Extension of MCP and IP Joints

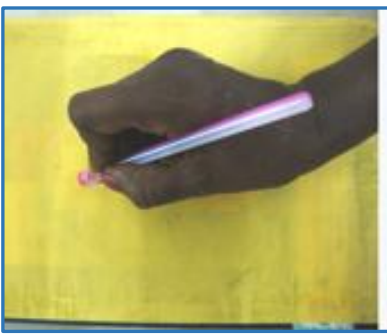

Pinch Strength

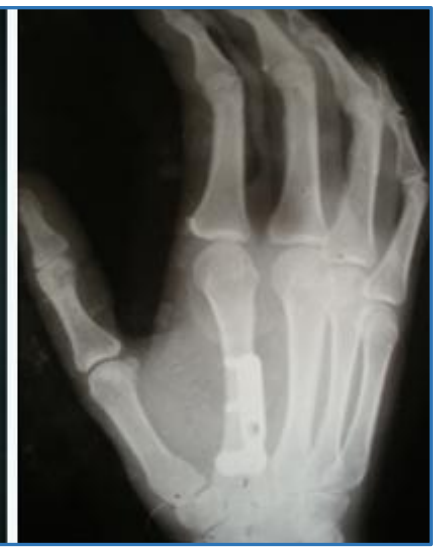

After Fixation \& IP Joints
Flexion of MCP

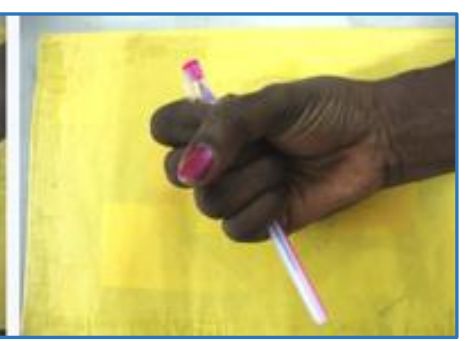

Grip Strength

Case 2

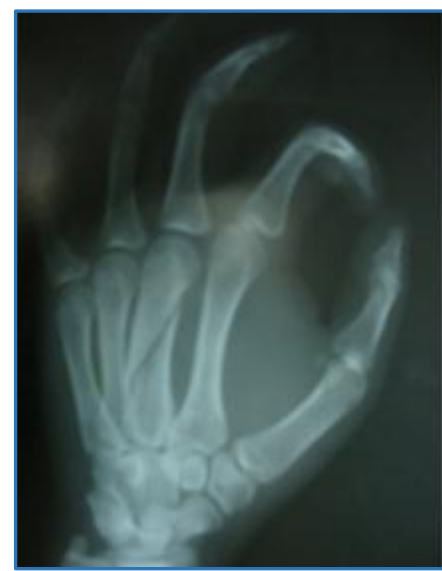

Pre-op

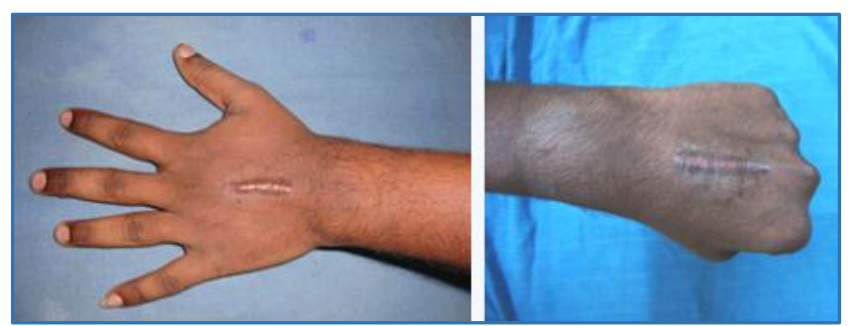

Extension of MCP, IP joints

Flexion of MCP, IP Joints

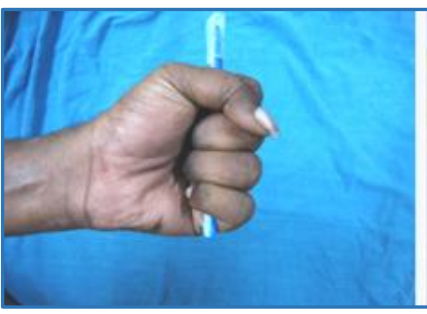

Grip Strength

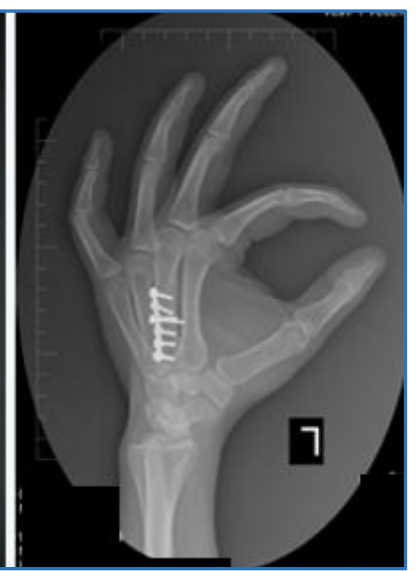

Fixation with \#Union

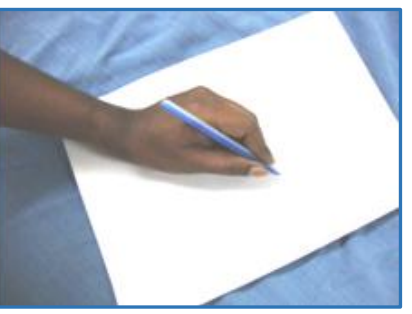

Pinch Strength

Case 3

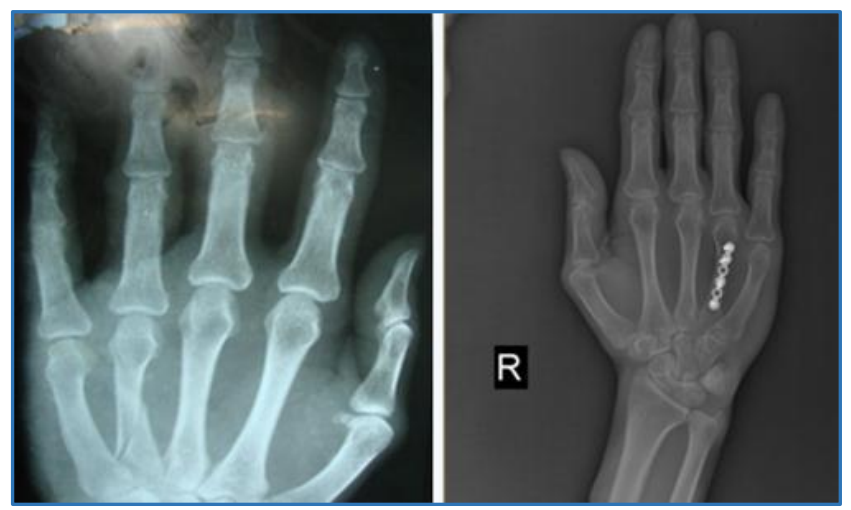

Pre-op

Fixation with Bone Union

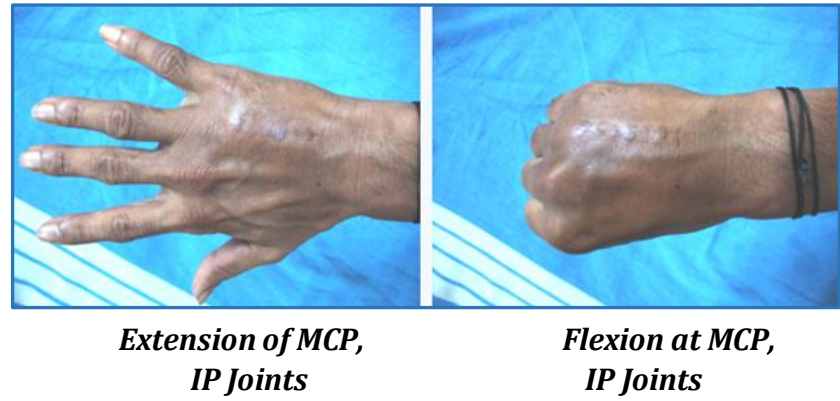




\section{Case 4}

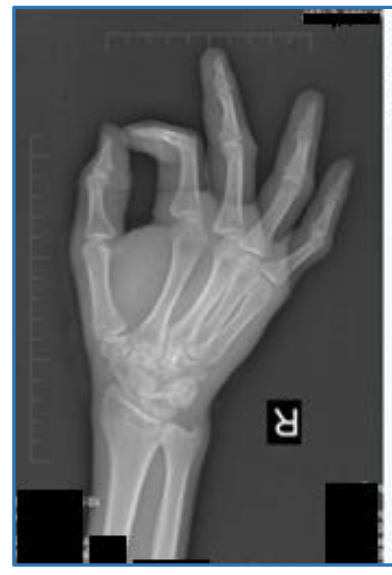

Pre-op

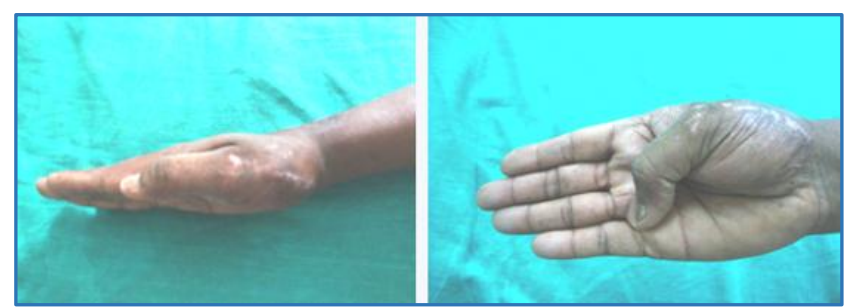

Adduction of Thumb

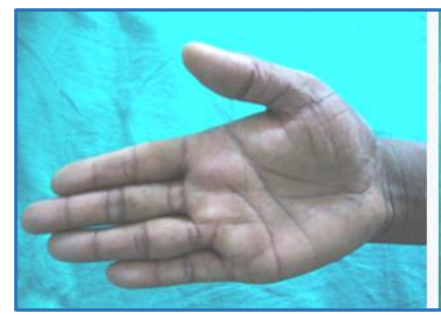

Extension of Thumb

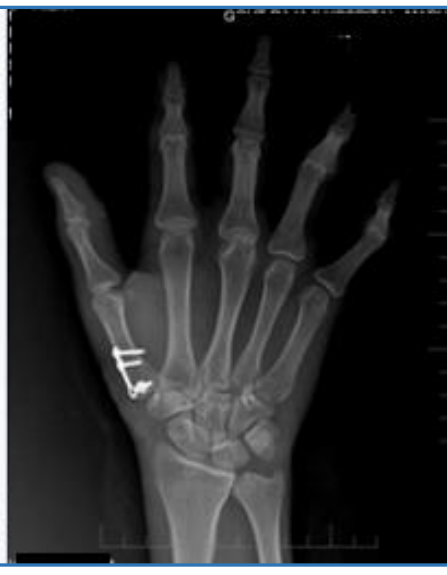

After Fixation
Flexion of Thumb

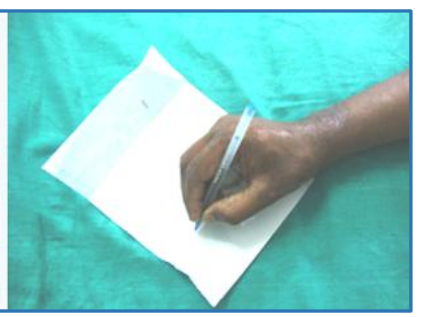

Pinch Strength

Case 5

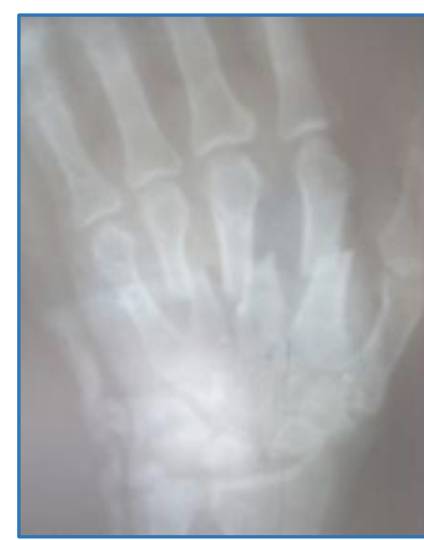

Pre-op

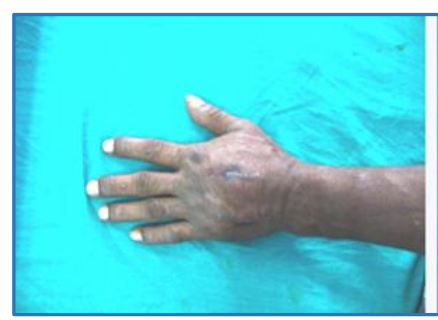

Extension of MCP, IP Joints

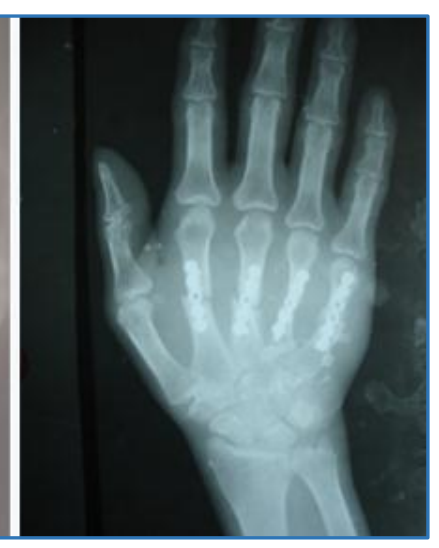

After Fixation

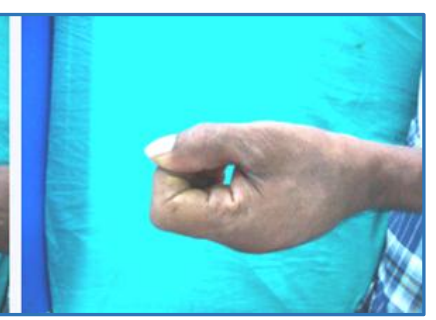

Flexion at MCP, IP Joints

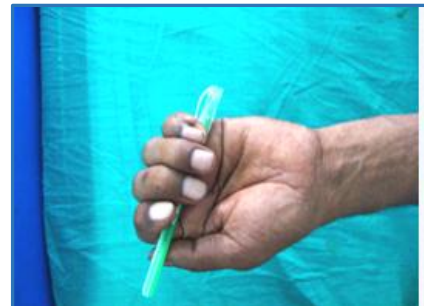

Grip Strength

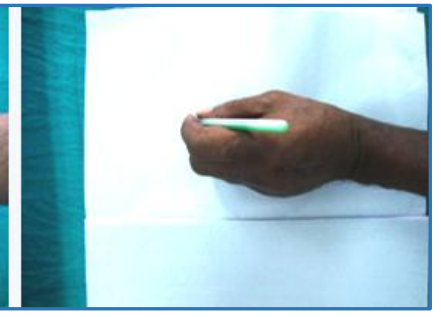

Pinch Strength

Case 6

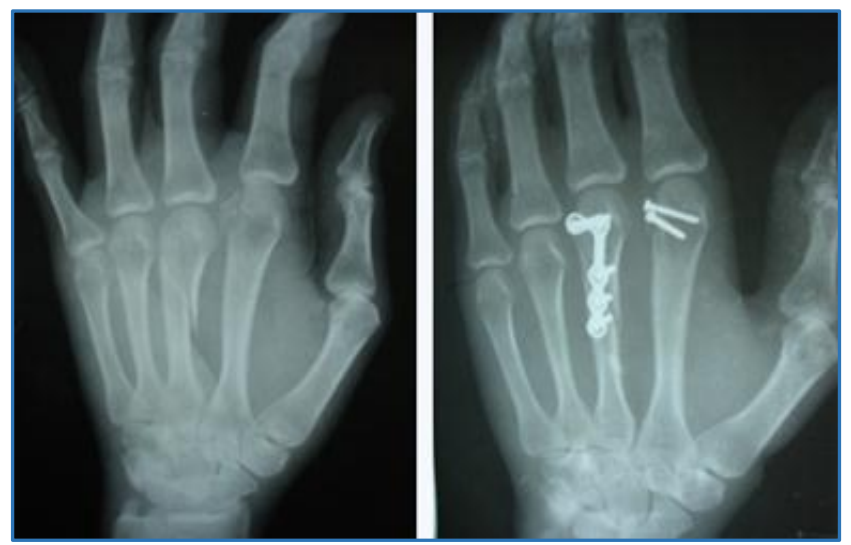

Pre-op

After fixation

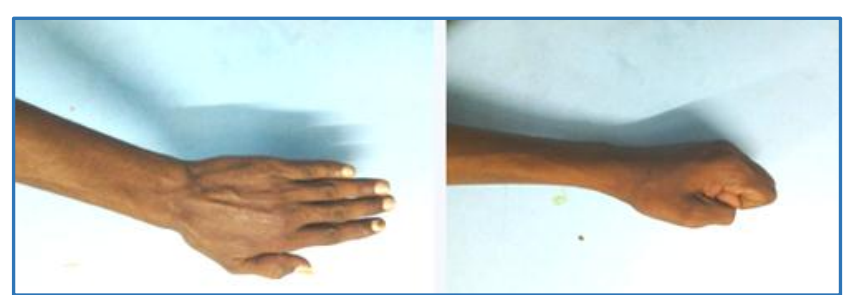

Extension of MCP, IP Joints

Flexion at MCP, IP Joints

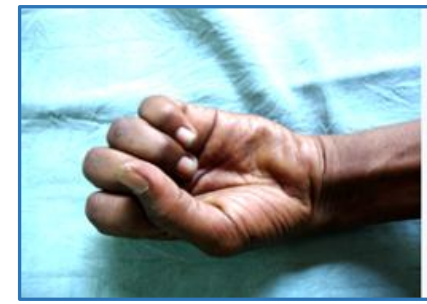

Grip Strength

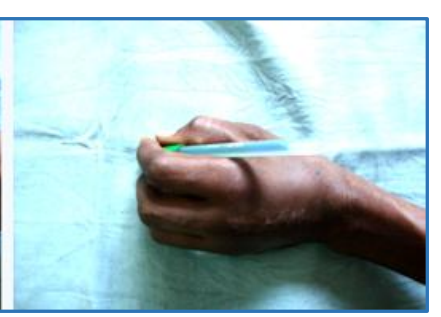

Pinch Strength

Case 7

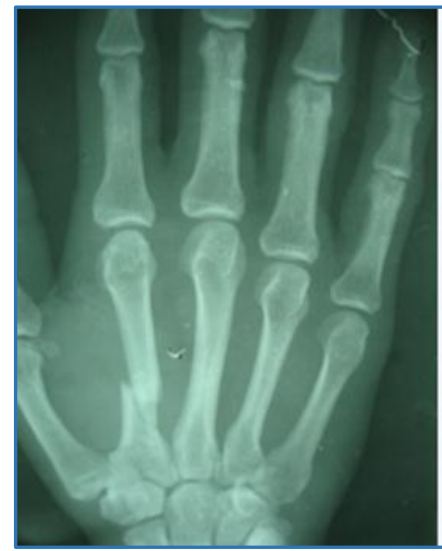

Pre-op

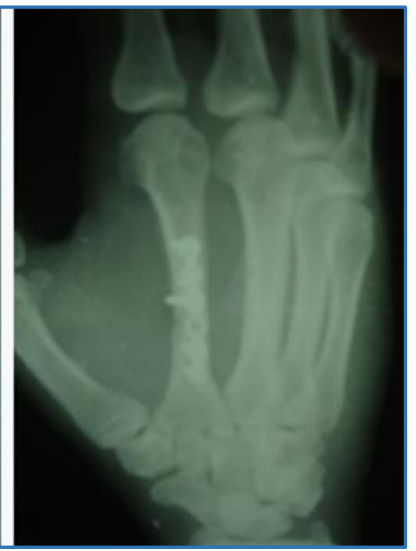

After Fixation 


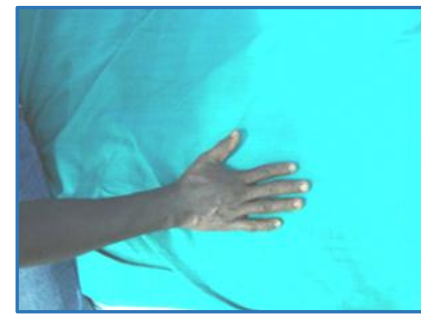

Extension of MCP, IP Joints

Case 8

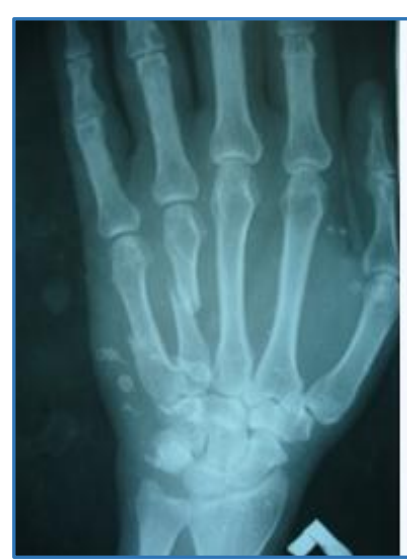

Pre-op

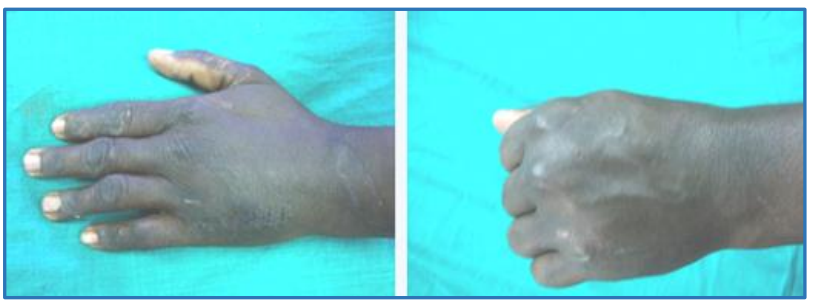

Extension of MCP, IP Joints

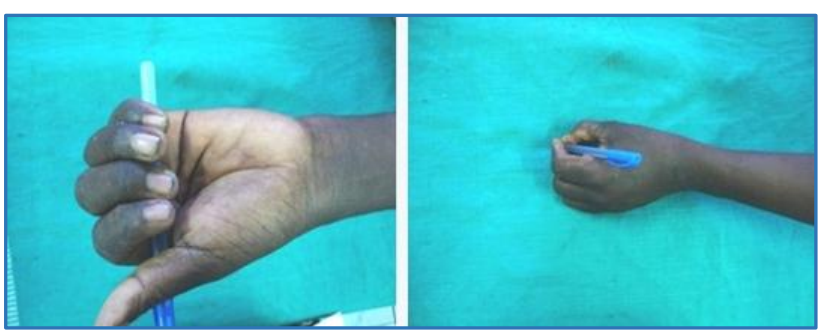

Grip Strength

Pinch Strength

\section{Case 9}

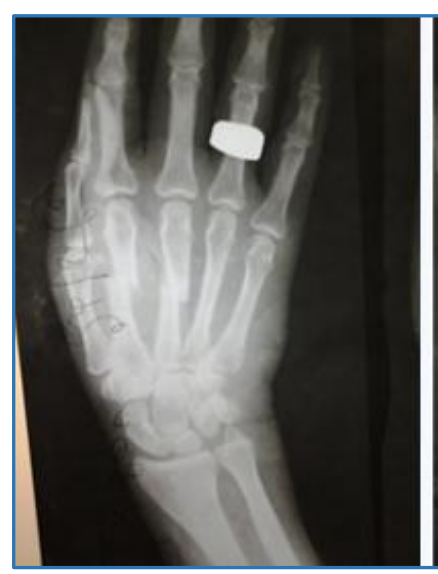

Pre-op

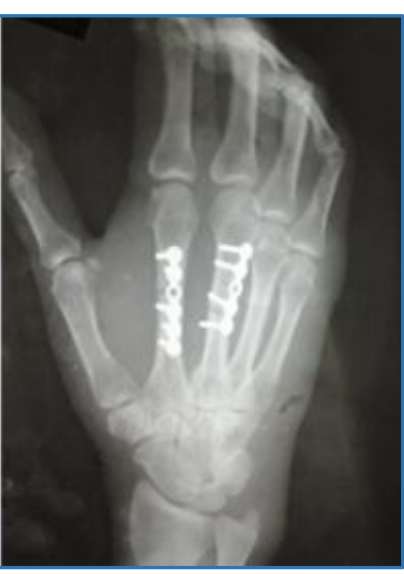

After Fixation

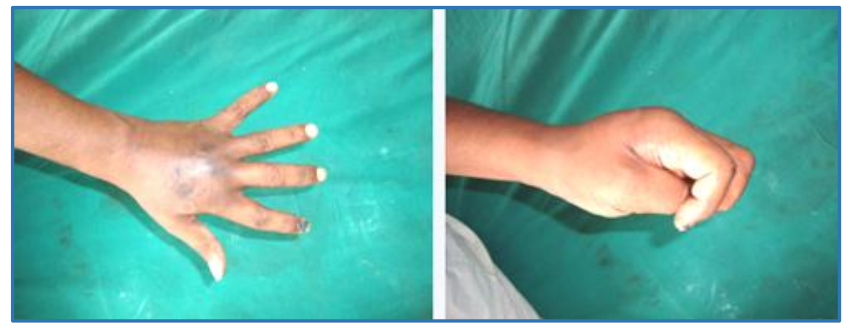

Extension of MCP, IP Joints

Flexion at MCP, IP Joints

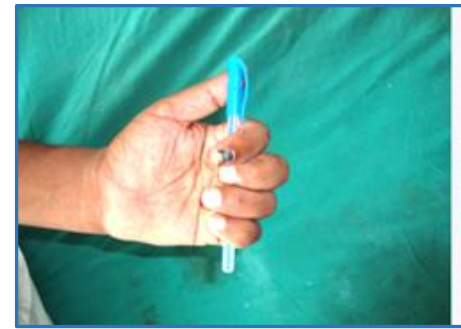

Grip Strength

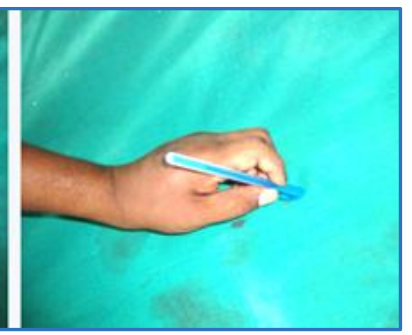

Pinch Strength
Case 10

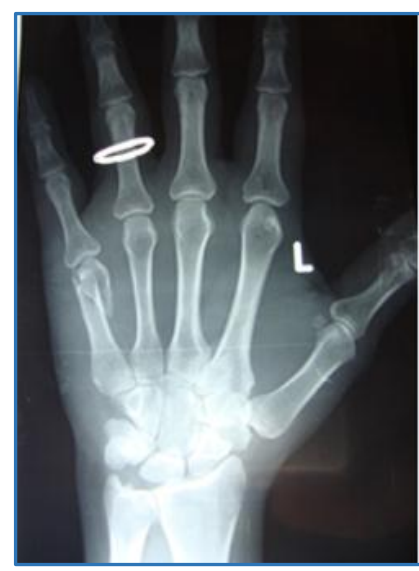

\#Neck of $5^{\text {th }}$ Metacarpal

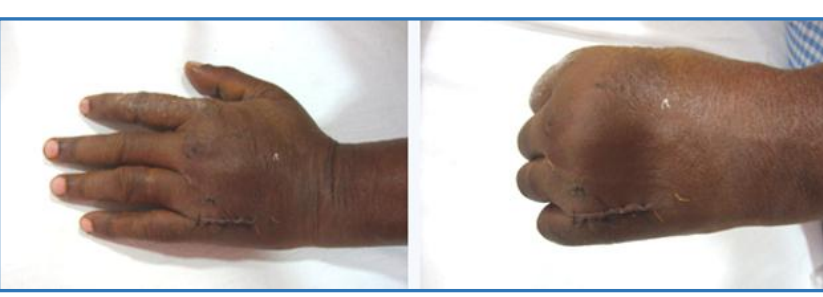

Extension of MCP \& IP Joints

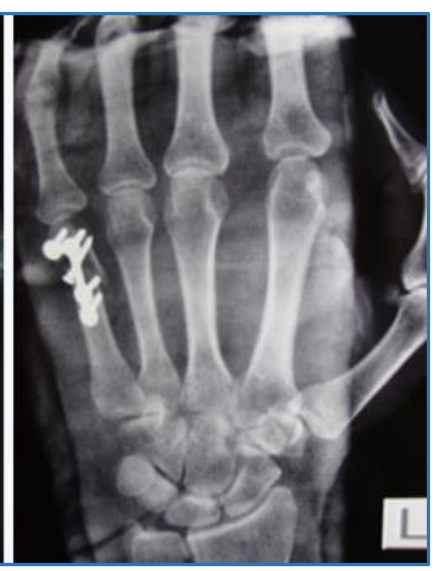

After Fixation

\section{Pitfalls and their Management}

\section{Infection}

Two cases developed wound infection, both were superficial infections. Pus culture for sensitivity was sent in two cases and treated with appropriate antibiotics and regular dressings. The superficial infections subsided with treatment for 3 weeks and none of the cases required implant exit.

\section{Finger Stiffness}

2 Patients with multiple metacarpal fractures developed finger stiffness and one case had fractures in all the four metacarpals and the other had fracture involving two metacarpals. The patients were put on strict regimen involving active 
mobilisation exercises. Eventually, all patients had improved range of movements following physiotherapy.

\section{Complications}

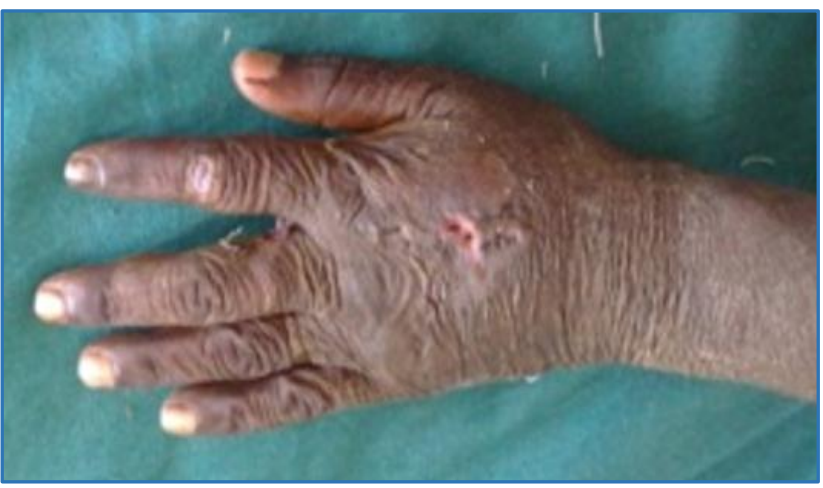

Wound Infection

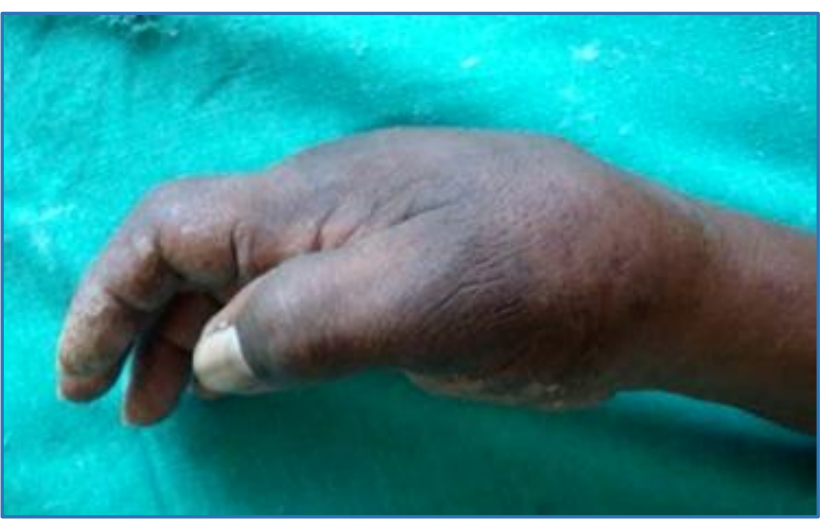

Stiffness

\section{RESULTS}

20 patients were included in this study. 6 patients had multiple metacarpal fractures (30\% cases). Right hand was involved in 11 of the patients (55\%). 2 out of 20 were female patients (20\%). All the 20 patients who underwent open reduction and internal fixation with plate osteosynthesis for unstable ${ }^{[2]}$ metacarpal fractures achieved bone union (100\%). In most of the cases, bony union was seen between 6-8 weeks, average period being 7.2 weeks (range 6-12 weeks). Spiral and oblique fractures united at 6 weeks, transverse and comminuted fractures united at around 8 weeks.

Functional outcome assessed by ASSH (American Society for Surgery of the Hand) TAF (Total Active Flexion) score was excellent in 16 patients (80\%), good in 2 patients $(10 \%)$, fair in one patient $(5 \%)$, poor in one patient $(5 \%)$. The overall results are satisfactory.

2 patients developed superficial wound infection, both were the case of multiple metacarpal fractures (both of these cases had involvement of two metacarpals). Both these cases with superficial infection settled with daily dressing and antibiotics. 2 patients had stiffness of metacarpophalangeal and interphalangeal joints and both were cases of multiple metacarpal fractures for whom physiotherapy was continued and patients showed improved range of motion, and the results in these patients were fair \& poor.

None of the patients in our study developed tendon irritation, this is due to extra cautious effort taken to cover the plate (low profile plate) with soft tissue (periosteum) for free gliding of overlying extensor tendon. No cases had angular or rotational displacement of fractures. No cases had implant breakage. None of the patients required implant removal.

\section{Analysis of Functional Outcome}

The functional outcome was assessed using American Society for Surgery of the Hand (ASSH) Total Active Flexion Score (TAF) and the following results were obtained.

\begin{tabular}{|c|c|c|}
\hline Grading & No. of Cases & Percentage \\
\hline Excellent & 16 & 80 \\
\hline Good & 2 & 10 \\
\hline Fair & 1 & 5 \\
\hline Poor & 1 & 5 \\
\hline \multicolumn{2}{|r|}{ ASSH-TAF Score - Overall Results } \\
\hline
\end{tabular}

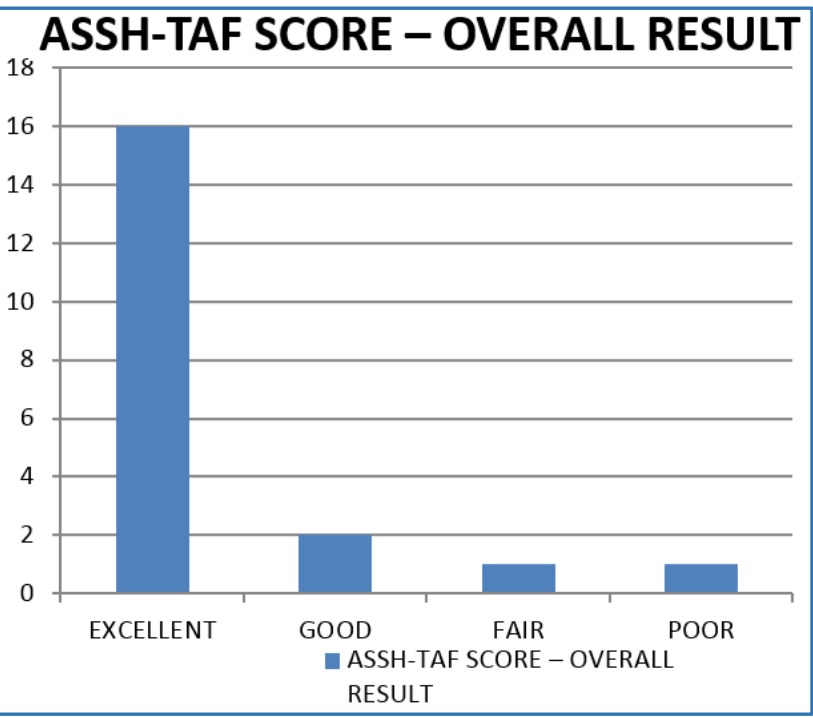

\section{DISCUSSION}

Most of the metacarpal fractures are stable before or after closed reduction and are managed successfully by conservative method of protective splinting followed by early mobilisation.(1,8) Only a small percentage of metacarpal fractures are unstable and in these patients the functional results following closed treatment are unsatisfactory. These are the cases indicated for open reduction and internal fixation which are usually less than $5 \%$ of hand fractures. $(6,9)$ James et al(10) reported that closed method used in treatment of unstable fractures had loss of function in $77 \%$ of fingers.

Open reduction and internal fixation with $\mathrm{K}$ wire(11) is one of the treatment modalities in these unstable fractures but they provide less rigid fixation and are rotationally unstable, there is increased association of pin tract infection, and problems due to protruding ends of $\mathrm{K}$-wire are significant. Interosseous wiring with $\mathrm{K}$ - wire although provides rigid fixation equivalent to plating is useful only in transverse diaphyseal fractures.

Metacarpal fractures can be fixed with external fixator.(12-16) Report by Shehadi et al(13) showed full return of total range of motions in up to $100 \%$ of metacarpal fractures treated with external fixator. This mode of fixation is useful in compound metacarpal fractures with bone loss. But the routine use of external fixator is discouraged as there is loosening of construct following pin tract infection leading to 
loss of fixation and there is difficulty in constructing and applying the fixator.

Intramedullary fixation with pre-bent $\mathrm{K}$ - wires was used for transverse and short oblique fractures.(17-20) They provide comparable functional outcome with plate and screw fixation. But there is incidence of loss of reduction, penetration of metacarpophalangeal joint by hardware, thus necessitating a second surgery for hardware removal.

There are many literature studies showing satisfactory results of unstable metacarpal and phalangeal fractures treated with $\mathrm{AO}$ mini plate and screws.(21-32) A study by Souer et al(33) showed good functional outcome by total active motion more than $230^{\circ}$ in 18 of 19 patients for whom plate fixation was done in closed unstable metacarpal fractures. Another study by Gupta et al(11) showed excellent functional outcome with total active movements more than $230^{\circ}$ in all of his patients of unstable metacarpal fractures treated with plate fixation. Another study by Dabezies Schutte(25) showed no complication in 27 unstable metacarpal fractures treated with plate fixation. Low complication rate seen in our study was similar to these results.

In our study on 20 patients, 2 patients developed superficial wound infection. In both these cases of superficial infection, there was wound discharge on second postoperative day which settled with daily dressing and antibiotics and this does not affect the final outcome. Two patients with multiple metacarpal fractures developed finger stiffness and one case had fractures in all the four metacarpals and the other had fracture involving two metacarpals. Eventually, all patients had improved ROM following physiotherapy.

In Unstable Metacarpal Fractures, Plate Fixation is a Better Option for Several Reasons, (34)

1. They provide stable fixation in all unstable metacarpal fractures, thus allowing early mobilisation of fingers.

2. Shortening seen in multiple metacarpal fractures which was corrected by plating which restores the power of interosseous muscles thereby retaining the grip strength of hand.

3. Multiple metacarpal fractures are usually associated with severe soft tissue injuries. In these unstable metacarpal fractures, treatment with plate osteosynthesis provides anatomical reduction of fracture with rigid stabilisation allowing early mobilisation of joints without loss of reduction, thus preventing stiffness and providing good functional results.

In our study of unstable metacarpal fractures treated with plate osteosynthesis, all the cases showed bone union (100\%). The functional result assessed by American Society for Surgery of the Hand (ASSH) Total Active Flexion score showed excellent result in $80 \%$ of the patients ( 16 of 20 cases), good in $10 \%$ of cases ( 2 of 20 cases). Stable and rigid fixation provided by mini plates and screws allowed early mobilisation of fingers thereby preventing stiffness leading to overall good functional results. Although there were $10 \%$ ( 2 cases) of superficial infections, all settled with regular dressing and antibiotics without affecting final functional outcome.

\section{CONCLUSION}

Plate and screw fixation is a good option for treating closed unstable metacarpal fractures, where other modalities of fixation are less effective, the rigid stable fixation provided by plating which withstands load without failure allowed early mobilisation and achieved good functional results .

Detailed clinical and radiological assessment of fracture, careful preoperative planning, meticulous dissection, precision in surgical technique (coverage of plate with soft tissue) and choosing the correct implant (low profile plate) are critical in achieving good results and minimising the complications.

\section{REFERENCES}

[1] Barton N. Conservative treatment of articular fractures in the hand. J Hand Surg Am 1989;14(2 Pt 2):386-90.

[2] Mumtaz MU, Farooq MA, Rasool AA, et al. Unstable metacarpal and phalangeal fractures: treatment by internal fixation by using $\mathrm{AO}$ mini-fragment plates and screws. Ulus Travma Acil Cerrahi Derg 2010;16(4):334-8.

[3] Lutz R, Sailer M, Zimmermann R, et al. Closed reduction transarticular Kirschner wire fixation versus open reduction internal fixation in the treatment of Bennett's fracture dislocation. J Hand Surg [Br] 2003;28(2):142-7.

[4] Gropper PT, Bowen V. Cerclage wiring of metacarpal fractures. Clin Orthop Relat Res 1984;188:203-7.

[5] Ozer K, Gillani S, Williams A, et al. Comparison of intramedullary nailing versus plate-screw fixation of extra-articular metacarpal fractures. J Hand Surg Am 2008;33(10):1724-31.

[6] Stern PJ. Fractures of the metacarpals and phalanges. $4^{\text {th }}$ edn. In: Green DP. (eds). Operative hand surgery. Vol 1. New York, Churchill Livingstone, 1999:711-71.

[7] Ouellette EA, Freeland AE. Use of the minicondylar plate in metacarpal and phalangeal fractures. Clin Orthop Relat Res 1996;327:38-46.

[8] Wright TA. Early mobilization in fractures of the metacarpals and phalanges. Can J Surg 1968;11(4):491-8.

[9] Amadio PC. Fractures of the hand and the wrist. In: Jupiter JB. (eds.) Flynn's hand surgery. Williams \& Wilkins, Baltimore, 1991:122-85.

[10] James JI. Fractures of the proximal and middle phalanges of the fingers. Acta Orthop Scand 1962;32:401-12.

[11] Gupta R, Singh R, Siwach RC, et al. Evaluation of surgical stabilization of metacarpal and phalangeal fractures of hand. Indian J Orthop 2007;41(3):224-9.

[12] Parsons SW, Fitzgerald JA, Shearer JR. External fixation of unstable metacarpal and phalangeal fractures. J Hand Surg Br 1992;17(2):151-5.

[13] Shehadi SI. External fixation of metacarpal and phalangeal fractures. J Hand Surg Am 1991;16(3):54450.

[14] Schuind F, Donkerwolcke M, Burny F. External minifixation for treatment of closed fractures of the metacarpal bones. J Orthop Trauma 1991;5(2):146-52.

[15] Pritsch M, Engel J, Farin I. Manipulation and external fixation of metacarpal fractures. J Bone Joint Surg Am 1981;63(8):1289-91.

[16] Buchler U. The small AO external fixator in hand surgery. Injury 1994;25(Suppl 4):S-D55-63. 
[17] Gonzalez MH, Igram CM, Hall RF. Flexible intramedullary nailing for metacarpal fractures. J Hand Surg Am 1995;20(3):382-7.

[18] Orbay JL, Indriago I, Gonzalez E, et al. Percutaneous fixation of metacarpal fractures. Op Tech Plast Reconstruct Surg 2002;9(4):138-42.

[19] Gonzalez $\mathrm{MH}$, Hall RF. Intramedullary fixation of metacarpal and proximal phalangeal fractures of the hand. Clin Orthop Relat Res 1996;327:47-54.

[20] Itadera E, Hiwatari R, Moriya $H$, et al. Closed intramedullary fixation for metacarpal fractures using J-shaped nail. Hand Surg 2008;13(3):139-45.

[21] Agarwal AK, Pickford MA. Experience with a new ultralow-profile osteosynthesis system for fractures of the metacarpals and phalanges. Ann Plast Surg 2006;57(2):206-12.

[22] Bosscha K, Snellen JP. Internal fixation of metacarpal and phalangeal fractures with $\mathrm{AO}$ minifragment screws and plates: a prospective study. Injury 1993;24(3):166-8.

[23] Chen SH, Wei FC, Chen HC, et al. Miniature plates and screws in acute complex hand injury. J Trauma 1994;37(2):237-42.

[24] Ford DJ, el-Hadidi S, Lunn PG, et al. Fractures of the metacarpals: treatment by A. 0 . screw and plate fixation. J Hand Surg Br 1987;12(1):34-7.

[25] Dabezies EJ, Schutte JP. Fixation of metacarpal and phalangeal fractures with miniature plates and screws. J Hand Surg Am 1986;11(2):283-8.
[26] Bu"chler U, Fischer T. Use of a minicondylar plate for metacarpal and phalangeal periarticular injuries. Clin Orthop Relat Res 1987;214:53-8.

[27] Diwaker HN, Stothard J. The role of internal fixation in closed fractures of the proximal phalanges and metacarpals in adults. J Hand Surg Br 1986;11(1):1038.

[28] Hastings H, Carroll C. Treatment of closed articular fractures of the metacarpophalangeal and proximal interphalangeal joints. Hand Clin 1988;4(3):503-27.

[29] Melone CP. Rigid fixation of phalangeal and metacarpal fractures. Orthop Clin North Am 1986;17(3):421-35.

[30] Stern PJ, Wieser MJ, Reilly DG. Complications of plate fixation in the hand skeleton. Clin Orthop Relat Res 1987;214:59-65.

[31] Thakore HK. Osteosynthesis for the unstable fracture of the hand. J Hand Surg Br 1986;11(3):417-21.

[32] Trevisan C, Morganti A, Casiraghi A, et al. Low severity metacarpal and phalangeal fractures treated with miniature plates and screws. Arch Orthop Trauma Surg 2004;124(10):675-80.

[33] Souer JS, Mudgal CS. Plate fixation in closed ipsilateral multiple metacarpal fractures. J Hand Surg Eur Vol 2008;33(6):740-4.

[34] Soni A, Gulati A, Basi JL. Outcome of closed ipsilateral metacarpal fractures treated with mini fragment plates and screws: a prospective study. J Orthop Traumatol 2012;13(1):29-33. 